\title{
The legacy of Frank H. Knight for the politics of financial governance
}

\author{
Chris Clarke (D) \\ University of Warwick, Coventry, UK \\ Corresponding author. Email: c.d.clarke@warwick.ac.uk
}

(Received 31 October 2020; revised 10 May 2021; accepted 10 May 2021; first published online 15 June 2021)

\begin{abstract}
The politics of financial governance under conditions of uncertainty has re-emerged as a significant issue for scholars of International Political Economy and related fields, not least because of the fallout from the 2007-2008 financial crisis. In this article I assess the legacy of Frank H. Knight's Risk, Uncertainty, and Profit for debates about reconceptualising financial governance and fostering financial stability. I argue Knight's book is productive in assisting understanding of the fallacies of the 'risk-based' economic theory tending to underpin financial governance, in particular drawing attention to the limitations of social scientific knowledge that reduce governance capacity and increase uncertainty in financial markets. I further argue, after Knight's deliberately paradoxical approach, that uncertainty in finance might be beyond regulation but at the same time there is still a societal need to attempt to achieve a politics of uncertainty that can cope with ignorance of the future through experimental governmental efforts.
\end{abstract}

Keywords: Financial governance; finance theory; Frank H. Knight; risk; uncertainty

That the world of finance is characterised by uncertainty and this has implications for its governance is an idea that has regained renewed attention since the financial crisis 2007-2008. Scholars of International Political Economy (IPE) and related fields have in particular considered how the crisis demonstrated that, at the very least, financial markets operate as much in an environment of uncertainty as they do under conditions of risk (e.g. Kirshner, 2014; Nelson and Katzenstein, 2014; Lockwood, 2015; Lockwood and Nelson, 2018). Likewise, though usually dismissed by much of the mainstream, influential economists have also reinvigorated interest in the notion that uncertainty is central to understanding financial markets and their malfunctioning (e.g. Frydman and Goldber, 2011; Kay and King, 2020). In his seminal text Risk, Uncertainty, and Profit, Frank H. Knight conceptualised uncertainty as distinct from risk, which provides an intellectual touchstone for much of this work. Knight (1921: 233) writes:

The practical difference between the two categories, risk and uncertainty, is that in the former the distribution of the outcome in a group of instances is known ... while in the case of uncertainty this is not true, the reason being in general that it is impossible to form a group of instances, because the situation dealt with is in a high degree unique.

In this article I explore how Knight's Risk, Uncertainty, and Profit complicates the accounts of uncertainty currently prevalent in discussions of financial governance. I argue Knight offers a way of expanding the terms of debate beyond those perspectives that theorise financial governance from what might be termed a 'risk-based regulation' approach, by lending intellectual authority and 
conceptual support to a notion of uncertainty beyond regulation. The former position essentially holds that uncertainty in finance is synonymous with risk and can be tamed through an appropriate institutional structure, the latter that a new politics of uncertainty is required that can come to terms with the limits of social knowledge produced by uncertainty. To be clear, the contention that financial markets operate under conditions of uncertainty beyond regulation is not the same as an argument that they should not be subject to governance, conventionally understood. By contrast, an implication of Knight's analysis is that social policy, especially in financial governance, needs a more fundamental rethinking of how governance institutions can even begin to attempt to negotiate the politics of uncertainty given the inherent and significant limits to knowledge faced. After Knight's deliberately paradoxical approach (Burgin, 2009), that uncertainty is beyond regulation does not evacuate the need to foster a politics of uncertainty that can attempt to cope with uncertainty through deliberative and experimental efforts in financial governance. In other words, recognition that the financial system exceeds full predictability and control should not be 'mistaken for political quietism' but instead used to 'open up space for deliberation about how to proceed in the face of irreducible uncertainty' (Lockwood, 2015: 749). In place of pervasive faith in the science of risk and the perfectibility of systems of risk-based financial governance, which were brought into doubt by the financial crisis, this rethinking is seemingly as necessary now as it was a century ago.

The contribution provides an assessment of Knight for theorising the politics of financial governance, especially in terms of the institutional solutions proposed to reconfigure the international system in the name of 'financial stability'. The argument of the article is sympathetic to Knight's core insights about uncertainty, especially as it moves analysis and policy away from a prioritisation of risk-based governance. I stress how his analysis that a world of uncertainty demands an appreciation of the limits to knowledge serves as a vital platform from which to illuminate contemporary discussions of financial stability. However, while it cannot be expected that a text written a century ago will have 'direct' insights into today's world, there are areas of Knight's work that contain potential limitations. As Knight (1921: 51) himself might put it, the assumptions made and resulting implications need to be more fully 'brought to the surface and emphasized'. In short, I pursue the argument that a limiting feature of Knight's book is that while it presents an account of the ideal-type economic and philosophical problem of uncertainty, it offers less in terms of specifying the radical political implications of uncertainty. What institutional and IPE scholars are left with, at least in many existing interpretations of Knightian uncertainty, are calls for market-based institutions - typically organised around the notion that risk-based governance is perfectly applicable in certain bounded domains - that arguably do not allow for the political implications of uncertainty to be fully recognised. I develop conceptual lines of argument from recent literature on the politics of financial governance to showcase the analytical space for this more political and radical account of uncertainty.

The article is structured as follows. In Section 1 I introduce Knight's text, in order to situate his account and outline its central claims, principally on the issues of uncertainty as distinct from risk and the implications of uncertainty for limits to knowledge about the future. In Section 2, I outline how the concept of Knightian uncertainty has tended to be deployed in the study of economic governance. This is pursued through a review of the resurgence of interest in uncertainty in the IPE literature. In Section 3, I discuss Knightian uncertainty distinguished from Keynesian uncertainty, which can be read as providing a more socialised emphasis based on intersubjective knowledge and with which more direct implications can be drawn for the design of governance institutions. In the final section, I position Knight's work in contemporary analysis of the economic theory underpinning the politics of financial governance. I emphasise the institutional aspects of financial governance, understanding institutions, broadly speaking, as the socially created products of an evolutionary process (Blyth et al., 2011).

\section{Knightian uncertainty}

Knight pursues an explicitly self-reflexive analysis in Risk, Uncertainty, and Profit. He elucidates the intentions of his enquiry and carefully demarcates the limits of his own project. Knight (1921: 22) 
describes his study as 'an inquiry into the causes of the failure of ideal competition to be fully realized in fact'. He is unambiguous in terms of suggesting that while the 'general principles' of lived experience might conform to competitive processes in economic terms, in no sense is a full system of free enterprise or perfect competition ever fully actualised or experienced (Knight, 1921: 9). This theme is recurrent throughout Risk, Uncertainty, and Profit and is recognised in the specialist literature as an anchoring point for his oeuvre (Boyd, 1997; Burgin, 2009; Cowan, 2016: 12). In Knight's (1921: 51) view, it is uncertainty that is 'the most important underlying difference between the conditions which theory is compelled to assume and those which exist in fact'. This presence or absence of uncertainty is the 'distinction between the perfect competition of theory and the remote approach which is made to it by the actual competition of, say, twentieth-century United States' (Knight, 1921: 19). Knight (1921: 19) is interested in explaining why the world as it is experienced cannot live up to a model of perfect competition and his 'answer' is uncertainty.

It is notable that Knight opens Risk, Uncertainty, and Profit with a critical discussion of the limitations of neoclassical Economics of his time as a discipline, in particular drawing a comparison with the natural sciences and highlighting the limitations of economic theory based on the problem of imperfect knowledge. Knight (1921: 5) writes: 'theoretical economics has been much less successful than theoretical physics in making the procedure [i.e. theoretical enquiry] useful, largely because it has failed to make its nature and limitations explicit and clear'. One such limitation he identifies is the danger of downplaying 'other-regarding motives' (Knight, 1921: 182). More broadly in the book, Knight's (1921: viii) form of analysis is one in which he attempts to precisely demarcate the fundamental features of free enterprise and why economic theory fails to account for them. This analytical task, he explains, 'must be radically separated from all questions of defense or criticism of the system under examination' (Knight, 1921: viii). An effort at impartiality with regards to free enterprise is noteworthy in terms of how Knight conducts his analysis and is an essential feature of his approach to social policy. Indeed Knight (1921: viii) does not necessarily defend capitalism: 'The net result of the inquiry is by no means a defense of the existing order. On the contrary, it is probably to emphasize the inherent defects of free enterprise'.

Of note at this point is Knight's approach to historical contingency throughout Risk, Uncertainty, and Profit. Knight (1921: 27; 12) makes critical remarks about socialist scholars, yet he shares with historical materialist thinkers an appreciation of the historical specificity of capitalism. He is clear that free enterprise 'is not necessary or inevitable, not the only conceivable form of organization' (Knight, 1921: 271). The forceful way he speaks of social institutions as being subject to the judgement of 'what the majority of the people think' also indicates he accepts that they are dependent on the provisional consent of society's members (Knight, 1921: 360). Even on private property as a social institution, Knight (1921: 359-360) writes 'society has the unquestionable right to change or abolish it at will'. What might be stressed through a Knightian lens is the provisional nature of institutional arrangements given that they ought to be subject to ongoing consent and change should always be viewed as possible. In fact, change over time - and the constant nature of change - is a foundational aspect of Risk, Uncertainty, and Profit more generally and serves to illustrate the limitations of economic theory in Knight's view. That neoclassical economic theory was 'too static' and needed a 'more dynamic dimension to the otherwise static notion of market equilibrium' has been acknowledged as one of Knight's major contributions (Cowan, 2016: 60). This contribution centres on Knight's well-known comments about profit, discussed here in terms set out in his text as opposed to secondary accounts.

For Knight (1921: 197-198), under 'free enterprise', profit is a process linked to the anticipation of future wants by the entrepreneur. It is 'changes in conditions [that] give rise to profit by upsetting anticipations and producing a divergence between costs and selling price, which would otherwise be equalized by competition' (Knight, 1921: 198). In other words, change - and specifically the fact that future changes are unpredictable - is what makes anticipation of future outcomes foundational to the possibility of profit (Knight, 1921: 311). To be sure, this is distinct from the view that profit is the 'reward' for 'risk-taking', which Knight (1921: 363) calls plainly mistaken. It is true to say 
that he identifies a unique and fundamental place for 'speculation' in free enterprise, in the sense that it is an instrument 'for the specialization of uncertainty' (Knight, 1921: 255). In other words, speculators are those people who specialise in 'uncertainty-bearing'. But Knight has a precise understanding of speculation, distinct from the term that became a target of criticism as a form of economic activity detached from, or even harmful to, productive activity. For Knight (1921: 226), as a business decision, speculation is more of an attempt to 'figure' the future, to 'estimate' the outcome of a proposition. This account is what leads Knight (1921: 19) to his statement that uncertainty is 'radically distinct' from risk. In essence, while risks are 'a quantity susceptible of measurement', uncertainty represents something completely 'unmeasurable' (Knight, 1921: 19-20).

This account should not be read as an ideological account of the superior intellect or a defence of the entrepreneur, which at times can be recited by even the most careful of accounts of Knightian uncertainty. Notably, for Knight (1921: 230; 233), 'the striking feature of the judging faculty is its liability to error' because on his view the exercise of judgment about future outcomes is based on fallible opinion not absolute fact. Knight (1921: 283) instead stresses that the success of any particular entrepreneur is just as much the outcome of 'luck' as ability, and that what is more influential in terms of rates of profit is 'the rashness or timidity of entrepreneurs (actual and potential) as a class in bidding up the prices of productive services'. Somewhat provocatively in this context, Knight (1921: 129) puts forward a 'conclusion as to social policy', which is the 'insistence that 'society' must get rid of the idea that because income is 'earned' it is 'deserved' and not otherwise'.

A central simplification of the risk-based view of economic activity that Knight (1921: 197) criticises is the 'assumption of practical omniscience on the part of every member of the competitive system'. This is contained within Knight's analysis of the limitations to knowledge about the social world. With reference to social action, he writes: 'The essence of the situation is action according to opinion, of greater or less foundation and value, neither entire ignorance nor complete and perfect information, but partial knowledge' (Knight, 1921: 199). Knight (1921: 198) suggests that what is crucial for understanding uncertainty is 'imperfect knowledge of the future, a consequence of change, not change as such'. He further argues that it is difficult to conceptually separate 'between the discovery of new facts and the production of change in the facts themselves as objects of knowledge' (Knight, 1921: 339). Again, the key issue for Knight is uncertainty understood as a problem of knowledge. The ability to produce knowledge about the future is difficult because of change: 'in an absolutely unchanging world the future would be accurately foreknown, since it would be exactly like the past' (Knight, 1921: 313). Furthermore, the 'most fundamentally and irretrievably uncertain phases or factors of progress are those which amount essentially to the increase of knowledge as such' (Knight, 1921: 318).

For Knight (1921: 46) the institution of insurance is the result of 'an elementary development of business organization to combine a sufficient number of cases' of known risks so that mathematical laws of probability can be used. Yet different insurance practices to an extent remain indeterminate, displaying 'a wide range of variation in the accuracy of measurement of probability which they secure' (Knight, 1921: 246-247). Beyond known risks, uncertainty presents a much more fundamental problem for classification. In practice most classifications of relevant situations are not as homogenous as mathematical probability would imply, but nor are they as idiosyncratic as to provide no possible form of grouping and a degree of measurement (Knight, 1921: 246-247). In chapter VII, Knight details at great length classifications as they relate to probabilistic outcomes, but he does not seek to seek classificatory devices for types of change, per se. On his view, there are significant limitations to processes of classification of change, which is an issue made even more substantial by the fact that change is pervasive. In fact, Knight (1921: 235) appears to understand change as an inexorable feature of contemporary society, and as such uncertainty is also constant: 'Life is mostly made up of uncertainties', he writes. Knight (1921: 199) views change as something relentless and insists it is 'a world of change in which we live, and a world of uncertainty'.

The aspect of Knight's analysis worth emphasising at this point is that this acceptance of the limits to knowledge about change itself is significant. The conditions that constitute situations of uncertainty are themselves potentially unknowable, the stuff of ignorance, leaving an expansive reading of the 
consequences of Knightian uncertainty possible. For his part, Knight (1921: 313) elucidates an expansive depiction of the problem of limited knowledge when he writes:

We live in a world full of contradiction and paradox, a fact of which perhaps the most fundamental illustration is this: that the existence of a problem of knowledge depends on the future being different from the past, while the possibility of the solution of the problem depends on the future being like the past.

However, issues remain unresolved in Knight's overall treatment of change in Risk, Uncertainty, and Profit, in part acknowledged in the text itself. Clearly, Knight is aware of the importance of studying change and indeed devotes Chapter $\mathrm{V}$ to the factors that must be studied to understand change. At the same time, he submits that 'no such ambitious [a] program can be entered upon' as 'a survey of all possible changes ... to both value and distribution phenomena, the prices of consumption goods and of productive services' and so on (Knight, 1921: 147). In other words, Knight explicitly acknowledges that even in studies using simplifying assumptions in order to depict a world of perfect competition, it is still extremely difficult to comprehend and systematise the full universe of potentially relevant change in the social world as it is experienced. This boundary to an analysis of 'change with uncertainty absent' is illuminating. For Knight's (1921: 198) argument, it specifically requires 'the separating in our study the effects of change from the effects of ignorance of the future'. Knight thus relies on something of a conceptual leap, though plausible, that what matters most is not the nature of change itself but the limitations of knowledge that mean change cannot be fully anticipated. Yet, at the same time, this incompleteness permits a great degree of ambiguity as to what constitutes relevant 'change', especially when attempting to think through the implications of his arguments about uncertainty in different contexts. In other words, Knight leaves open the question of what might be called the 'boundary conditions' of uncertainty - that is, the types and degrees of change that might fall either into conditions of risk or into conditions of uncertainty. Knight is clear that uncertainty is prevalent in early twentieth-century capitalism, but the implications of his own analysis about limited knowledge about change prevent him from fully specifying the nature and boundaries of all relevant change.

In summary, Knight offers an expansive and rich account of uncertainty, which is deemed a necessary and constant condition of life given the limited nature of knowledge about future change. Knight stops short of offering a full systematic account of what constitutes relevant change, instead choosing to emphasise the inherent limitations to knowledge of all types in terms of knowing and prediction. In a characteristically self-reflexive style, this includes in his own analysis. The point to foreground is that it is this emphasis on limited knowledge that is most illuminating in Knight's work. I wish to mobilise Knight's thinking to underscore a reading of uncertainty that lends support to the notion it is beyond regulation. The central aspect of this reading is what might be called the paradox of uncertain knowledge, a way of engaging Knightian uncertainty as the 'Achilles heel of social enquiry' (Jarvis, 2010: 6). A return to Knight's comments on the social science endeavour and his critique of economic theory is devastating but still productive. As has been emphasised, limitations to knowledge of the future are a key aspect of economic experience that forestalls the possibility of perfect competition (Knight, 1997 [1923]: 43). As has been indicated, for Knight 'the essential evil of uncertainty' is the impossibility of complete knowledge (Emmett, 1999: 31). In the final chapter of Risk, Uncertainty and Profit, Knight (1921: 369) concludes: 'we shall only insist again on the limitations of the economic view of social organization as a mechanism for satisfying human wants in any static and hence scientifically describable sense of the term'. Perhaps, then, a reinvigoration of a questioning of the discipline of Economics - and IPE for that matter - as an institution is one of the lasting implications of Knight's book. A multitude of scholars have pursued such a productive endeavour for some time. For instance, as Mirowski (2010: 418) outlines, the attempt at fully understanding the financial crisis should 'begin with renunciation of the obsession with culprits and turn more concertedly towards longer-term historical structures, and perhaps even more importantly, the role of economic theory in the framing of those structures'. The pay-off of this approach is a more self-reflexive analysis of the landscape of 
knowledge that goes into financial governance, including but not limited to moments of crisis that inspire reform. The next section serves to pursue the reading of Knightian uncertainty as beyond regulation with a discussion of how uncertainty tends to be conceptualised in studies of the politics of financial governance in IPE.

\section{Uncertainty in IPE}

In the IPE literature, Knightian uncertainty is typically discussed in relation to the relative merits of rationalism. For instance, Kirshner (2014: 48) rightly notes that the sharp distinction Knight draws between risk and uncertainty is 'incompatible with rational expectations'. Kirshner (2014: 49) appeals to Knightian uncertainty in support of the notion that in practice 'rational individuals reach different conclusions when presented with the same facts'. Similarly, Blyth (2002) develops a reading of Knightian uncertainty for IPE analysis more broadly to challenge the dominant rational institutionalist approaches in the field. Blyth (2002: 8) begins with the criticism that many institutionalist theories tend to overlook the significance of uncertainty by treating it as synonymous with risk. Since people cannot anticipate outcomes of decisions under situations of uncertainty it is impossible to assign probabilities to those possible outcomes. Against the rationalist outlook, in conditions of uncertainty, 'agents' interests become something to be explained, rather than something with which to do the explaining' (Blyth, 2002: 9).

Invoking a critique of rationalism in an analysis of the financial crisis 2007-2008, Nelson and Katzenstein (2014: 362) demonstrate how market actors and policymakers operate in a world of both risk and uncertainty, compelling them at times to operate according to social conventions as a substitute for rational decision-making to help 'stabilize uncertain environments'. Serving to complicate a depiction of financial markets operating according to risk-based probabilities, this account emphasises that conventions serve as 'social templates for managing epistemic uncertainty' but that they cannot 'eliminate uncertainty' (Nelson and Katzenstein, 2014: 362-263). Imprecise knowledge about the future means that decision-making in and about financial markets operates, at least in part, under conditions of uncertainty (Nelson and Katzenstein, 2014: 266; Lockwood and Nelson, 2018: 167). For Nelson and Katzenstein (2014: 363), to better understand financial markets, IPE scholars should pursue analysis that can 'encompass the toolkits both rationalist and sociological styles of analysis provide'. In other words, social conventions offer a means to 'complement and enrich rationalist explanations' so they 'deserve more attention' (Nelson and Katzenstein, 2014: 364). In analysing the financial crisis, Nelson and Katzenstein (2014: 369) suggest that in certain empirical domains, such as excessive risk-taking, the 'risk-based, rationalist optic' provides compelling explanation. By contrast, in other domains, such as mortgage securitization, risk-management models and central bank practices, they argue that 'the evidence suggests an important role for social conventions in shaping agents' decision making' (Nelson and Katzenstein, 2014: 369). In other words, they make a distinction between different empirical domains according to whether or not conditions of uncertainty pertain.

The critique of rationalism is consistent with Knight's stated position. Indeed, he labelled himself an 'irrationalist' on the basis that he was sceptical that a science of conduct was possible given that motivations often lack set principles and stable causes (Cowan, 2016: 42). In key passages, Knight (1921: 347) contends uncertainty is one of the fundamental facts of life. It is as ineradicable from business decisions as from those in any other field'. Moreover, he writes that 'the logic of our conduct assumes real indeterminateness, real change, discontinuity' (Knight, 1921: 311 emphasis in original). Hyman Minsky (1942, L4, 6), when taught by Knight on his course on institutionalism at the University of Chicago, scribbled in his lecture notes: 'rationality inherently contradictory'. Despite notable differences between their work Minsky appreciated the importance of uncertainty. He suggests to understand financial instability it is necessary to produce analysis that recognises the 'problems involved in decision-making in the face of the intrinsically irrational fact of uncertainty' (Minsky, 2016 [1982]: 121-122). Relatedly, Knight's (1921: 202) view on 'reason' is that a 'sharp distinction' 
with perception cannot be drawn. Opinions, judgements and even 'consciousness in the simplest situation', are for Knight (1921: 202) 'an imaginative construct'. As such, Knightian uncertainty has been correctly identified as a 'black hole beyond rationality' (Jarvis, 2010: 20).

The critique of rationalism developed in IPE is productive in terms of emphasising the need to pay greater attention to social conventions in economic agency, a criticism of neoclassical approaches also well established in the heterodox Economics literature. As Nelson and Katzenstein (2014: 363) put it: 'The rationalist view that we live in a world of only calculable risk is too simple and leaves us with a dangerously incomplete view of economic life'. However, the way Knightian uncertainty has been utilised in this critique appears to suggest that there are still certain boundary conditions to uncertainty. That is, some domains or periods of time are depicted as uncertain, necessitating the need for nonrationalist approaches, while in other instances rationalist analysis is deemed appropriate. It can appear as though conventional or constructivist accounts of behaviour almost become an appendage to rationalist approaches - to 'complement and enrich rationalist explanations' (Nelson and Katzenstein, 2014: 364). Put another way, 'the institutions and conventions that serve to stabilize expectations sometimes lead market players and regulatory authorities to experience their environments as domains of measurable risk' (Lockwood and Nelson, 2018: 167 emphasis added). While an important corrective, then, the critique of rationalism in IPE based on the concept of uncertainty might beg the question of what it is about the constitutional features of certain empirical domains, such as risk-taking according to the 'mechanism of competition' (Nelson and Katzenstein, 2014: 372), that make these particular domains subject to risk as opposed to uncertainty? A related boundary condition is seemingly the designation of 'sophisticated financial markets' distinguished from other forms of market agency (Lockwood and Nelson, 2018: 166-167). While an insightful perspective on the valuation practices of professional money managers working for financial institutions, this take says less about the outlook of those 'outside' formal financial markets or those 'non-professionals', for example everyday mortgagers in the subprime crisis, who are also making decisions that presumably affect potentially relevant financial change.

Alongside boundaries drawn around particular empirical domains, uncertainty also appears to be distinctly periodised in some accounts when incorporated into IPE. Blyth (2002: 9) notes that taking uncertainty seriously allows for recognition that 'what constitutes an economic crisis as a crisis is not a self-apparent phenomenon'. Constructivist IPE scholars have been keen to emphasise that economic crises themselves are constructed, in the sense that they always have to be socially mediated and narrated as crises. In this perspective the designation of crisis 'becomes an act of intervention where sources of uncertainty are diagnosed and constructed' (Blyth, 2002: 10). From this standpoint, though, uncertainty is in a sense theorised as a temporary phenomenon as it chiefly operates during periods of 'economic instability' or 'crisis' (Blyth, 2002: 9). That is, uncertainty is understood as associated with 'unique' moments in time (and place) that are essentially exceptions from the norm. Bracketing away from 'how uncertainty is generated', Blyth $(2002: 35$, fn76; 9) introduces them as 'situations regarded by contemporary agents as unique events'. For Blyth (2002: 36), Knightian uncertainty is relevant for 'periods of economic crisis', which are 'radically different' to those environments defined by risk. Crucially, on this view, 'situations of Knightian uncertainty ... occur during the periodic breakdowns of capitalist economies' (Blyth, 2002: 32 emphasis added).

To be sure, to highlight the drawing of boundaries around uncertainty is not in itself a devastating critique of such interventions. It might simply be the case that in financial markets, for instance, relevant economic agents experience both risk and uncertainty and the boundaries between the two can be identified, at least heuristically, for analytical purposes (Lockwood and Nelson, 2018: 167). Extrapolated to theories of governance the same conceptualisation of risk alongside uncertainty could also be productive. In fact, Seybert and Katzenstein (2018) have developed an ambitious yet nuanced conception of 'protean power' to broaden analysis beyond power conceived in terms of control, which operates under conditions of risk, to better explain dynamics of changeable power under conditions of uncertainty. They define protean power as 'the effect of improvisational and innovative responses to uncertainty that arise from actors' creativity and agility in response to uncertainty' 
(Seybert and Katzenstein, 2018: 4). Katzenstein and Seybert's (2018: 48) perspective emphasises the crucial role of uncertainty in social life because its implications are that 'the past is not prologue' and there can be conditions experienced in which 'there is no basis for agents to settle on what the probability distribution [of future outcomes] looks like'. The protean power outlook thus also approaches 'risk-based power calculations' as useful 'in many situations', while positioning it alongside protean power that 'arises in situations of deep-seated uncertainty that actors often experience as a crisis' (Seybert and Katzenstein, 2018: 4-6).

In this section, I have outlined how uncertainty and the work of Knight in particular has been incorporated into IPE analysis. The concept of uncertainty has been developed so as to challenge the rational institutionalist accounts that hold interests as given. On this view, with economic ideas or conventions given appropriate explanatory power, risk-based regulatory institutions are deemed possible in certain domains. The identification of boundary conditions for uncertainty is not problematic for IPE analysis per se. However, based on Knight's account of uncertainty outlined above there are some inconsistencies left when read in the context of the rest of his contribution in Risk, Uncertainty, and Profit in that the boundaries of relevant change are themselves unknown. In the next section I show how 'bounded uncertainty' is actually more plausible under a Keynesian account of uncertainty, whereas a Knightian interpretation produces a greater questioning of the limits of knowledge of the future. This makes Knightian uncertainty less amenable as a neat supplement to a 'risk-based, rationalist optic' than might first appear. Moreover, this is a particularly pressing issue because traditionally there has been a high degree of ambiguity around the nature of change itself in IPE (Dannreuther and Lekhi, 2000: 576). While the bounded conceptualisation of uncertainty opens a number of productive lines of analysis, I foreground a different reading of Knightian uncertainty arguably closer to Knight's text.

\section{Knightian and Keynesian uncertainty}

Keynes and Knight are often discussed together as thinkers who emphasised the role of 'nonroutine change' and knowledge problems at the centre of their analysis (Frydman and Goldberg, 2011: 17). Keynes put forward a specific notion of uncertainty that was foundational to his thinking (Davidson, 1994). Integrated into IPE, Kirshner (2014: 6) emphasises how Knight shared Keynes' rejection of rational expectations. Similarly, Best (2008: 364) writes: 'Like Knight, Keynes saw economic decision making as based on conventional rather than perfectly rational thinking' (Best, 2008: 364). She explains, however, that a key difference is that 'unlike Knight, Keynes saw this process as unavoidably social'. By implication Keynesian social policy solutions are more collective in design, to be contrasted with Knight's emphasis on 'the superior rational capacities of a few expert speculators and entrepreneurs' (Best, 2008: 364). Best (2008: 364) therefore turns to Keynes to suggest that his notion of uncertainty is actually closer to her use of the concept 'ambiguity'. This refers to 'those forms of indeterminacy that can neither be responded to through calculation, like risk, nor addressed through the provision of better information or individual intuition, like uncertainty' (Best, 2008: 370).

In certain respects, Knight also views decision-making, even the decisions of 'expert speculators and entrepreneurs', as inherently social. Like Keynes, whose book A Treatise on Probability appeared in the same year as Risk, Uncertainty, and Profit, Knight is interested in the intersubjective foundations of knowledge. For instance, he explicitly mentions how confidence in one's own judgements is dependent on the degree of confidence held in authorities that share those views, while there is a process of 'mutual reinforcement' with others that operates in the formation of substantive opinions (Knight, 1921: 288; 1923/24: 147). Further, he writes that 'we even believe in ourselves because and in the measure that we think others believe in us' (Knight, 1921: 288). Yet it is true that Knight (1921: 288) refrains from attempting to systematically set out the intersubjective foundations of knowledge, as Keynes does, instead stating that the 'importance of indirect knowledge of fact through knowledge of others' knowledge is the point we wish to emphasize'. 
The common analysis of imperfect knowledge offered by Keynes and Knight still serves to foreground the limits of risk-based economic theory per se (Frydman and Goldberg, 2011: 162). If Knight's key distinction is that risk relates to outcomes for which it is possible to assign a probability statement and uncertainty to those for which it is not, then Keynes can be said to share this interpretation of uncertainty (Ciccarone, 2020: 87). For instance, this is how Keynes (1937: 213) makes a distinction between statements about the game of roulette, involving risk, and propositions about future commodity prices, involving uncertainty. Though they independently arrived at this view, then, Keynes shared Knight's distinction between risk and uncertainty and has been usefully taken up by a range of IPE scholars on this point to foreground the 'inherent limitations of probabilistic risk modelling' (Lockwood, 2015: 727).

At the same time, Keynes also specified a different interpretation of uncertainty based on the problems faced when attempting to anticipate the decision-making process of others (Ciccarone, 2020: 87). The inflection given to uncertainty here is defined less in terms of an unknowable future per se, as with Knight, and more in terms of the difficulty in assessing how other people are assessing the future (Keynes, 2018 [1936]: 137). Keynes placed emphasis more forcefully on intersubjective knowledge formation as opposed to the indeterminacy of the future. Thus, while both Knight and Keynes have uncertainty at the centre of their analysis of the shortcomings of capitalism, the implications of their accounts lead in different directions. In short, Knight uses uncertainty to explain the source of profit, as indicated in the first section above, whereas Keynes holds that uncertainty leads people to seek liquidity as a money balance to secure against an unpredictable future (Minsky, 2016 [1982]: 132; Cowan, 2016: 65). Though both interpretations of uncertainty are based on the limitations of knowledge claims about the future, Knight's 'looks to the future as the locus of indeterminacy rather than recognizing the ambiguous historicity of the present' (Best, 2008: 363). This leads Best (2008: 357 ) to suggest that 'Keynes provides a much more radical and social conception of the limits of political economic knowledge'. Best emphasises the ways in which Keynes goes further, or is at least more explicit, with the implications for social policy of his view that decision-making is a social process. Indeed, a central pillar of Keynesian Economics in this light can be read to grant consent to 'apt interventions' by political institutions to constrain cyclical uncertainty (Minsky, 2008 [1986]: 326; 364).

The different emphasis Knight and Keynes placed on uncertainty is thus important for discussions of financial governance. On the Keynesian account, to reduce uncertainty would be to tame finance through regulation and manage liquidity preferences. On the Knightian account, to reduce uncertainty would be to remove from the free enterprise system the source of profit and as such its own means of continuation. Knight of course does still hold it possible to moderate uncertainty by improving knowledge of the future through social organisations, but for him this comes at the potential cost in terms of individual freedom (Cowan, 2016: 71). He stresses how business activity can and does work to reduce uncertainty through creating appropriate organisations, but they are primarily driven by making money not public purpose (Cowan, 2016: 61). While Keynes saw uncertainty as 'an ontological entity that constrains knowledge and its dimensions', Knightian uncertainty can be read to have 'more profound implications and suggests greater limits to knowledge acquisition' (Jarvis, 2010: 16). On these grounds it is possible to read in Knight a notably expansive understanding of uncertainty that views it as a necessary and ever-present condition of free enterprise capitalism. If conditions of uncertainty are more general in this way, then the limitations of knowledge Knight identifies become potentially more demanding and relevant outside of periodic crises.

In contrast to a bounded conception of uncertainty as it tends to enter IPE, then, a more expansive reading of Knightian uncertainty is warranted and productive. Conditions of Knightian uncertainty do not just pertain to bounded or episodic conditions, narrowly defined, but a broader range of interactions in money and finance including those in ostensibly 'normal' times and everyday circumstances. This latter more expansive reading of Knightian uncertainty - implying that financial markets display enduring uncertainty conditions - offers a way of conceiving uncertainty, as indicated above, as something beyond regulation. The lasting legacy of Risk, Uncertainty, and Profit can then be understood in terms of a rethinking of the limits of financial governance, as the final section serves to unpack. 


\section{The limits of uncertain financial governance}

In the last decade a partial shift in orientation of global financial governance has led to greater recognition of uncertainty in the financial system and the possibility, if not likelihood, of future crises (Best, 2016: 40). This shift is centred on combating financial instability by reducing 'systemic risk' (Konings, 2016). Now well documented, increased conceptual and practical appreciation of systemic risk in financial markets has produced an epistemological revision to financial governance, most notably in terms of the rise of 'macroprudential regulation' (Baker, 2013; Datz, 2013). In short, the new macroprudential agenda has focused on financial institutions that are systemically important, as well as capital adequacy ratios for individual financial firms (Best, 2016: 46). While such action might serve to stabilise financial markets by reducing the risk attached to the complex interdependence of institutions, the conception of risk underpinning the agenda is understood in definable and probabilistic terms. It builds on the identification of large institutions' mismanagement of risk as responsible for the crisis and implies that better predictive models can be produced in response (Lockwood, 2015: 748). The risk-based outlook suggests that relevant institutions can and should be designed so as to reduce the likelihood of systemic breakdown through the reduction, or even elimination, of the causes of financial instability.

However, a critical reading is that a governance response founded on probabilistic risk gives credence to the logic of the view that risk management knowledge is both possible and perfectible. To understand the financial crisis as a problem of excessive risk-taking to be insured against in this way fosters a governance response, as has been witnessed, in terms of a focus on institutional inefficiencies and asymmetries in information' (Best, 2005: 16). It is not a move towards accepting the problems associated with limited knowledge of an uncertain future or a move towards acknowledging conditions of full Knightian uncertainty. For some, it is a failure to accept what for many scholars demonstrated yet again that 'the whole point about complex and open financial markets is that future outcomes are uncertain rather than risky' (Hodgson, 2009: 1214). Despite the problems of excessive and misplaced faith in risk management techniques associated with structured finance that contributed to the crisis (Esposito, 2013: 121; Tooze, 2019: 53), the response to the 2007-2008 crisis has according to some influential accounts been largely more of the same: a lack of meaningful regulatory reform in global finance has led the 2007-2008 financial crisis to be designated 'the status quo crisis' (Helleiner, 2014).

This is not to suggest there has been no development in the economic and finance theory underpinning financial governance in the last decade. For instance, influential economists Kay and King (2020) - who previously represented the economic orthodoxy for the past 50 years - appeal to Knight in Radical Uncertainty to provide a cutting critique of the continued use of economic modelling based on the assumption that the future is knowable. Their book centres on the prevalence of radical uncertainty as the chief source of the failures of the prediction and analysis leading to the global financial crisis 2007-2008. It is in a sense emblematic of a partial shift in thinking that has taken place. Knight has also been invoked by economists Frydman and Goldberg (2011:11-12) to support a key criticism of what they identify contemporary finance theory to have failed to learn from the financial crisis: scholars continue to attempt to account for risk using models that 'suppose that nonroutine change is irrelevant, as if nothing genuinely new can ever happen'. However, notably, their 'Imperfect Knowledge Economics' perspective developed in response still 'departs' from Knight and Keynes by making 'nonstandard use of probabilistic formalism' (Frydman and Goldberg, 2011: 165).

There are those approaches that go further, beyond a conception of 'taming finance', to one in which knowledge about uncertainty itself is a problem necessitating concern, and in which there are subsequent significant limitations to relevant institutional design (Salter and Tarko, 2019). From this perspective, to the extent that it is possible to reform and respond to a particular 'crisis', there is a requirement to build in potential to deal with permanent and radical conditions of uncertainty and even inevitable failure (Best, 2005). This has occurred to the extent that policymakers have pivoted to a working ontology that accepts that, '[t]aking systemic risk seriously means seeing the 
global financial system as not only complex, dynamic, and highly interconnected but also recognizing that because of this, it will inevitably be highly uncertain and prone to crisis' (Best, 2016: 48 emphasis added). It raises the question of whether or not uncertainty is ultimately 'beyond science and rationality and thus beyond a politics of control or a science of management and mitigation' (Jarvis, 2010: 17). This approach features in discourses of 'resilience' that have become prevalent in recent years (Salter and Tarko, 2019), especially associated with an engagement with complexity theory by influential central bank officials, such as Andrew Haldane at the Bank of England, and an outlook that essentially holds that 'the financial sector produces a form of uncertainty that cannot be addressed through traditional regulatory mechanisms' (Brassett and Holmes, 2016: 379). While productive and a radical departure for much economic and finance theory, the conceptual move to understanding financial markets in terms of complexity theory still holds that accurate modelling is possible for monitoring future uncertainty in financial markets (e.g. Battiston et al, 2016). Yet, this is problematic on Knightian terms since his very notion of uncertainty as radically distinct from risk moves social analysis away from risk understood in terms of 'complexity' (Blyth, 2002). In this regard, what Hodgson (2009: 1214) describes as 'the cult of metrication' maintains dominance even in the revised thinking.

One of the reasons for the continued supremacy of the risk-based outlook in global financial governance is perhaps that it 'expresses a deep desire for and faith in control' (Katzenstein and Seybert, 2018: 29). More fundamentally the spread of the ideal of risk management, as an embracing of ostensibly knowable uncertainty, has become a politically powerful force at least in part associated with the influence of orthodox economic theory in recent decades. Risk management has for some time been inserted into the 'fabric of everyday lives', as part of 'a fantasy that uncertainty could be both perfectly knowable and expertly managed' (Reddy, 1996; Aitken, 2015: 118). Notably, the economic theory on which risk management depends tends to assume that endogenous uncertainty is almost entirely absent from market interactions, so that the only remaining form of uncertainty is that which is caused by political action by the state or other political institutions (Best, 2008: 366). Yet on Knightian terms, such economic theory would be wrongheaded since uncertainty is inherent to the free enterprise system, not something exogenously created by non-market political actors.

An emphasis on the political consequences of the risk-based outlook is possible by more fully thinking through the implications of uncertainty in financial markets. As Lockwood (2015: 748) argues, 'acknowledging that financial systems are characterized by a level of uncertainty that exceeds probabilistic modeling calls for a different political sensibility, one not driven solely by attempts at prediction and control'. Reddy (1996) has some time ago developed this theme of understanding uncertainty in terms of political contestation. He explains how the radical implication of Knightian uncertainty is that it destabilises claims 'to the possession of reliable differential ability to anticipate, regulate or control the future' (Reddy, 1996: 228). On these grounds, for Reddy (1996: 228), it is then possible to create 'enlarged room for social and political contestation as to the meaning, importance and likelihood of various contending interpretations of the indeterminate future'. His reading of Knightian uncertainty advocates understanding the indeterminate future as an 'open political domain, rather than existing as an undemocratically and scientistically defined and 'mapped out' horizon of alternatives' (Reddy, 1996: 228). Financial governance would then be conceptualised beyond a riskbased view of better models to an expanded emphasis on generating the 'flexibility, resources, and political will to weather unforeseeable financial shocks' (Lockwood, 2015: 748-749). It would move away from 'the scientistic promise of calculation and control' (Reddy, 1996: 246). This position on governance is in a sense a more sceptical and pragmatic view, but does not necessarily negate the need for or ability of political institutions, instead casting them in a more restrictive light, one in which there is a need for 'caution and humility' as Knight (1921:375) might put it. In short, by avoiding the conflation of uncertainty with risk it is possible to recognise 'the truly radical and irreducible nature of our ignorance about the future world, which makes ... it in turn an irreducibly political space' (Reddy, 1996: 242). In place of the 'ubiquitous language of risk management' perhaps a more 'public politics' is required 'to support an engagement with unknowable futures' (Power, 2004: 58). 
While there is need for caution in privileging the success and reach of economic theory at the expense of other forms of knowledge (Bryan et al., 2012: 308), a Knightian-inspired reading of the implications of uncertainty renews the need to continually question and problematise the limits of economic theory in the current era. The financial crisis offered a moment for self-reflection on questions of knowledge, yet to a large extent this invitation has not been accepted with scholars more often than not using existing problematics as lenses through which to understand money and finance after the crisis (Bryan et al., 2012). As Watson (2014: 8) argues, 'much of the political effort that has been expended to try to restart failing markets afresh has merely been a way of imagining new worlds on the basis of the old equations'. Notably, the renewal of interest in scholars such as Keynes and Minsky for their insights into the importance of the monetary system has been largely absent from mainstream Economics (Hodgson, 2009). The specific flaws in the way much economic theory has framed financial instability are varied, but the principal contours of the problem can be identified using insights from Knight. Chief amongst the limitations would be the practices of economic modelling that continue to operate beyond and to the exclusion of the 'the intractabilities of uncertainty, complexity and system openness in the real world' (Hodgson, 2009: 1217).

Knight's account of the limitations of the social science endeavour also serves as an 'ethical imperative' to pursue attempts to improve human understanding while recognising the provisional status of knowledge until today's 'truths' can be bettered (Boyd, 1997: xviii). A century later, in a climate of 'postfactual politics' (Tooze, 2019: 21), perhaps this imperative is more difficult to comprehend and navigate than ever. Recognising the limits of specialist knowledge, whether in economic theory or any other aspect of disciplinary convention, is something that is fraught with difficulty when 'antielite' conversations about expertise dominate mainstream politics, especially in major developed countries. Reddy's (1996: 248) plea to 'rehabilitate' the idea of 'irreducible indeterminacy, not amenable to authoritative or authoritarian 'expert' definition and measurement' sounds rather different in the political climate a quarter of a century later. Moreover, it is important to note that a focus on limitations to knowledge in the context of the financial crisis also serves to shift attention away from the equally important role of ignorance, which can itself be used as a 'political and commercial resource' (Davies and McGoey, 2012: 80). Perhaps the basis of such claims strays beyond the Knightian account of uncertainty, but what is clear is that Knight was 'profoundly sceptical of the idea of developing objective tools for predicting human action' (Jarvis, 2010: 13) and this scepticism was centrally directed at economic theory that failed to understand the basic contours of real-world economic experience. In this respect, given limitations to economic knowledge rarely fully acknowledged, perhaps greater recognition of the role of ignorance in financial governance - and of the limits to managing uncertainty that is beyond regulation - is one of the most important lasting insights of Risk, Uncertainty, and Profit.

\section{Conclusion}

The question 'what is money?' has recently re-emerged as a significant focus of analysis for scholars across a range of disciplines, as well as for international financial institutions such as the Bank for International Settlements (Frasser and Guzmán, 2020). This is perhaps to be expected given that the last decade has witnessed unprecedented central bank efforts to address financial instability (Salter and Tarko, 2019), reorganisation in the international monetary system (Murau, 2017; Murau et al., 2020), and novel advances in payment technologies, especially in terms of the emergence of new digital currencies (Luther, 2019; Smit et al., 2016). Minsky's financial instability hypothesis offers an important intellectual touchstone for much recent analysis (Wray, 2017; Ferri, 2019), not least because of its emphasis on endogenous instability as a cause of financial crises (Hodgson, 2009: 1207; Mirowski, 2010). Notable in this turn towards re-examining money and financial stability is the emphasis placed on the role of core features of the financial system in contemporary capitalism (Tooze, 2019). For instance, fractional reserve banking (Bauwens, 2017), and especially the creation of private credit money in such a system (Ülgen, 2014), have re-emerged as prime topics of concern. 
In general terms, money and financial stability are once again linked together as urgent issues conceptually, empirically, and politically.

Yet conventional economic theory can have relatively little to say on such matters, if for no other reason than money still tends to be viewed as a 'neutral measure', embodying 'the distinctly modern imaginary according to which we may speculate our way to a life that is immune to the uncertain effects of unpredictable events' (Konings, 2016: 271). For the most part it is a conventional, that is 'neutral', approach to money, that underpins institutional efforts to govern money at the international level. Relatedly, it has been suggested that conceptions of money should move away from essentialist accounts, to a more robust view that recognises its inherent ambiguities in a world dominated by credit money (Frasser and Guzmán, 2020). That credit money is the most systematically relevant form of money under conditions of financial globalisation is an argument that has made much ground since the crisis (Mehrling, 2011). Yet, crucially, future crises are themselves also deemed more likely given the 'inherent instability of credit money' (Murau et al., 2020: 14).

Studies of the worlds of money and finance still need greater appreciation of Knightian uncertainty. In this article, I have developed a reading of Knight that emphasises how his conception of uncertainty is that it is beyond regulation. Such a reading serves to clarify and build on what Knightian uncertainty can offer IPE and related fields. This reading was then mobilised with respect to contemporary debates about financial stability to draw attention to how economic knowledge limitations are often inadequately admitted. Knight (1921: 375) concludes that the 'existing order [is] not ideal, nor even good' but 'disagreement as to what we want' makes 'radical transformation' difficult. However, in the very last line of his book, he also emphasises that what is required is 'caution and humility in dealing with reconstruction proposals' (Knight, 1921: 375). Knight does not absolve political agency in bringing about social change but wishes to stress the need to recognise the 'caution and humility' such agency must shoulder. What is required, it seems from this discussion, is a means through which political deliberation can take place to explore 'disagreement as to what we want'.

\section{References}

Aitken, R. (2015), Fringe Finance: Crossing and Contesting the Borders of Global Capital, London: Routledge.

Baker, A. (2013), 'The New Political Economy of the Macroprudential Ideational Shift', New Political Economy, 18(1): 112-139.

Battiston, S., J. Doyne Farmer, A. Flache, D. Garlaschelli, A.G. Haldane, H. Heesterbeek, C. Hommes, C. Jaeger, R. May and M. Scheffer (2016), 'Complexity Theory and Financial Regulation', Science, 351(6275): 818-819.

Bauwens, M. (2017), 'The Ontology of Fractional Reserve Banking', Journal of Institutional Economics, 13(2): $447-466$.

Best, J. (2005), The Limits of Transparency: Ambiguity and the History of International Finance, Ithaca and London: Cornell University Press.

Best, J. (2008), 'Ambiguity, Uncertainty, and Risk: Rethinking Indeterminacy', International Political Sociology, 2(4): 355-374.

Best, J. (2016), 'When Crises Are Failures: Contested Metrics in International Finance and Development', International Political Sociology, 10(1): 39-55.

Blyth, M. (2002), Great Transformations: Economic Ideas and Institutional Change in the Twentieth Century, Cambridge: Cambridge University Press.

Blyth, M., G. Hodgson, O. Lewis and S. Steinmo (2011), 'Introduction to the Special Issue on the Evolution of Institutions', Journal of Institutional Economics, 7(3): 299-315.

Boyd, R. (1997), 'Introduction to the Transaction Edition', in F. Knight (ed.), (1997 [1935]) The Ethics of Competition, New Brunswick, NJ: Transaction, pp. vii-xxxii.

Brassett, J. and C. Holmes (2016), 'Building Resilient Finance? Uncertainty, complexity, and resistance', The British Journal of Politics and International Relations, 18(2): 370-388.

Bryan, D., R. Martin, J. Montgomerie and K. Williams (2012), 'An Important Failure: Knowledge Limits and the Financial Crisis', Economy and Society, 41(3): 299-315.

Burgin, A. (2009), 'The Radical Conservatism of Frank H. Knight', Modern Intellectual History, 6(3): 513-538.

Ciccarone, G. (2020), 'Market Versus Government Failures Under Risk and Under Uncertainty', Journal of Public Finance and Public Choice, 35(1): 81-106.

Cowan, D. (2016), Frank H. Knight: Prophet of Freedom, Basingstoke: Palgrave Macmillon.

Dannreuther, C. and R. Lekhi (2000), 'Globalization and the Political Economy of Risk', Review of International Political Economy, 7(4): 574-594. 
Datz, G. (2013), 'The Narrative of Complexity in the Crisis of Finance: Epistemological Challenge and Macroprudential Policy Response', New Political Economy, 18(4): 459-479.

Davidson, P. (1994), Post-Keynesian Macroeconomic Theory, Aldershot: Edward Elgar.

Davies, W. and L. McGoey (2012), 'Rationalities of Ignorance: On Financial Crisis and the Ambivalence of Neo-Liberal Epistemology', Economy and Society, 41(1): 64-83.

Emmett, R. (1999), 'The Economist and the Entrepreneur: Modernist Impulses in Risk, Uncertainty and Profit', History of Political Economy, 31(1): 29-52.

Esposito, E. (2013), 'The Structures of Uncertainty: Performativity and Unpredictability in Economic Operations', Economy and Society, 42(1): 102-129.

Ferri, P. (2019), Minsky's Moment: An Insider's View on the Economics of Hyman Minsky, Cheltenham: Edward Elgar.

Frasser, C. and G. Guzmán (2020), "What Do We Call Money? An Appraisal of the Money or Non-Money View", Journal of Institutional Economics, 16(1): 25-40.

Frydman, R. and M. D. Goldberg (2011), Beyond Mechanical Markets: Asset Price Swings, Risk, and the Role of the State, Princeton: Princeton University Press.

Helleiner, E. (2014), The Status Quo Crisis: Global Financial Governance After the 2008 Meltdown, Oxford and New York: Oxford University Press.

Hodgson, G. (2009), 'The Great Crash of 2008 and the Reform of Economics', Cambridge Journal of Economics, 33(6): 12051221.

Jarvis, D. (2010), 'Theorising Risk and Uncertainty in Social Enquiry: Exploring the Contribution of Frank Knight', History of Economics Review, 52(1): 1-26.

Katzenstein, P. and L. Seybert (2018), 'Uncertainty, Risk, Power and the Limits of International Relations Theory', in P. Katzenstein and L. Seybert (eds.), Protean Power: Exploring the Uncertain and Unexpected in World Politics, Cambridge: Cambridge University Press, pp. 27-56

Kay, J. and M. King (2020), Radical Uncertainty: Decision-Making for an Unknowable Future, London: The Bridge Street Press.

Keynes, J. M. (1921), Treatise on Probability, London: Macmillan.

Keynes, J. M. (1937), 'The General Theory of Employment', Quarterly Journal of Economics, 51(2): 209-223.

Keynes, J. M. (2018 [1936]), The General Theory of Employment, Interest and Money, London: Macmillan.

Kirshner, J. (2014), American Power After the Financial Crisis, Ithaca: Cornell University Press.

Knight, F. (1921), Risk, Uncertainty, and Profit, Boston, MA: Hart, Schaffner and Marx; Houghton Mifflin.

Knight, F. (1923/24), 'On Power: The Invincible Logic of Asceticism', in R. B. Emmett (ed), Frank H. Knight in Iowa City, 1919-1928, Bingley: Emerald Publishing Limited, pp.137-147.

Knight, F. (1997 [1923]), 'The Ethics of Competition', in F. Knight (ed), (1997 [1935]) The Ethics of Competition, New Brunswick, NJ: Transaction, pp. 33-67.

Konings, M. (2016), 'Governing the System: Risk, Finance, and Neoliberal Reason', European Journal of International Relations, 22(2): 268-288.

Lockwood, E. (2015), 'Predicting the Unpredictable: Value-at-Risk, Performativity, and the Politics of Financial Uncertainty', Review of International Political Economy, 22(4): 719-756.

Lockwood, E. and S. Nelson (2018), 'Incomplete Control: The Circulation of Power in Finance', in P. Katzenstein and L. Seybert (eds.), Protean Power: Exploring the Uncertain and Unexpected in World Politics, Cambridge: Cambridge University Press, pp. 166-187

Luther, W. (2019), 'Getting Off the Ground: The Case of Bitcoin', Journal of Institutional Economics, 15(2): 189-205.

Mehrling, P. (2011), The New Lombard Street. How the Fed Became the Dealer of Last Resort, Princeton: Princeton University Press.

Minsky, H. (1942), 'Lecture Notes on Institutionalism', Hyman P. Minsky Archive, 484. https://digitalcommons.bard.edu/ hm_archive/484 (accessed 12/10/20)

Minsky, H. (2008 [1986]), Stabilizing an Unstable Economy, New York: McGraw-Hill.

Minsky, H. (2016 [1982]), Can 'It' Happen Again?: Essays on Instability and Finance, Abingdon: Routledge Classics.

Mirowski, P. (2010), 'Inherent Vice: Minsky, Markomata, and the Tendency of Markets to Undermine Themselves', Journal of Institutional Economics, 6(4): 415-443.

Murau, S. (2017), 'Shadow Money and the Public Money Supply: The Impact of the 2007-2009 Financial Crisis on the Monetary System', Review of International Political Economy, 24(5): 802-838.

Murau, S., J. Rini and A. Haas (2020), 'The Evolution of the Offshore US-Dollar System: Past, Present and Four Possible Futures', Journal of Institutional Economics, 16(6): 767-783.

Nelson, S. C. and P. J. Katzenstein (2014), 'Uncertainty, Risk, and the Financial Crisis of 2008', International Organization, 68 (2): 361-392.

Power, M. (2004), The Risk Management of Everything: Rethinking the Politics of Uncertainty, London: Demos.

Reddy, S. G. (1996), 'Claims to Expert Knowledge and the Subversion of Democracy: The Triumph of Risk Over Uncertainty', Economy and Society, 25(2): 222-254. 
Salter, A. and V. Tarko (2019), 'Governing the Banking System: An Assessment of Resilience Based on Elinor Ostrom's Design Principles', Journal of Institutional Economics, 15(3): 505-519.

Seybert, L. and P. Katzenstein (2018), 'Protean Power and Control Power: Conceptual Analysis', in P. Katzenstein and L. Seybert (eds), Protean Power: Exploring the Uncertain and Unexpected in World Politics, Cambridge: Cambridge University Press, pp. 3-26.

Smit, J., F. Buekens and S. Du Plessis (2016), 'Cigarettes, Dollars and Bitcoins - An Essay on The Ontology of Money', Journal of Institutional Economics, 12(2): 327-347.

Tooze, A. (2019), Crashed: How a Decade of Financial Crises Changed the World, London: Penguin.

Ülgen, F. (2014), 'Schumpeterian Economic Development and Financial Innovations: A Conflicting Evolution', Journal of Institutional Economics, 10(2): 257-277.

Watson, M. (2014), Uneconomic Economics and the Crisis of the Model World, Basingstoke: Palgrave Macmillan.

Wray, L. R. (2017), Why Minsky Matters: An Introduction to the Work of a Maverick Economist, Princeton: Princeton University Press.

Cite this article: Clarke C (2021). The legacy of Frank H. Knight for the politics of financial governance. Journal of Institutional Economics 17, 973-987. https://doi.org/10.1017/S1744137421000436 